\title{
ASPECTOS DA GERMINAÇÃo E DESENVOLVIMENTO INICIAL DE PLÂNTULAS DE AROEIRA
}

\author{
Silvana de Paula Quintão Scalon ${ }^{1}$, Homero Scalon Filho' ${ }^{2}$, Tathiana Elisa Masetto ${ }^{3}$
}

(recebido: 30 de agosto de 2010; aceito: 28 de abril de 2012)

\begin{abstract}
RESUMO: A aroeira (Myracrodruon urundeuva) é uma espécie de grande importância econômica, em razão do aproveitamento da madeira, a extração de taninos e a utilização na farmacologia. Neste trabalho, objetivou-se avaliar os aspectos da germinação das sementes e do desenvolvimento inicial de aroeira em função de giberelina, substrato e luz, conduzidos em dois experimentos. No primeiro, utilizaram-se sementes embebidas durante 24 horas em água e em solução de giberelina $100 \mathrm{mg} . \mathrm{L}^{-1} \mathrm{e}$ sementes semeadas diretamente em bandejas de células, nos seguintes substratos: terra e areia nas proporções de $1: 1$ e 1:2 e Plantmax ${ }^{\circledR}$. No segundo experimento, as plântulas com $15 \mathrm{~cm}$ de comprimento foram transplantadas para sacos de polietileno preenchidos com terra+areia+cama de aviário semidecomposta (1:1:1) e foram mantidas em casa de vegetação durante 15 dias. Posteriormente, as mudas foram transferidas para as seguintes condições: $50 \%$ de sombreamento e pleno sol e foram pulverizadas com soluções de giberelina nas concentrações de $50 \mathrm{mg} . \mathrm{L}^{-1} \mathrm{e} 150 \mathrm{mg} . \mathrm{L}^{-1} \mathrm{e}$ apenas água para as mudas que serviram como controle. Sementes de aroeira não necessitam de pré-embebição em água ou em giberelina antes da semeadura. O melhor substrato para a germinação das sementes foi o Plantmax ${ }^{\circledR}$, sem necessidade de tratamentos pré-germinativos para obtenção de acima de $80 \%$ de sobrevivência de plântulas. As mudas desenvolvem melhor a pleno sol, sendo observado incremento em altura, diâmetro, área foliar, massas fresca e seca da parte aérea e da raiz em relação ao sombreamento. A aplicação de giberelina não influenciou as características de crescimento inicial das mudas de aroeira.
\end{abstract}

Palavras-chave: Tratamentos pré-germinativos, Myracrodruon urundeuva, Anacardiaceae, cerrado.

\section{GERMINATION AND INITIAL DEVELOPMENT OF AROEIRA (Myracrodruon urundeuva) SEEDLINGS}

\begin{abstract}
Aroeira has great economic importance due to its wood useful, tannins extraction and use in the pharmacology. The aim of this work was to evaluate the germination aspects and initial seedlings development of aroeira, under gibberellins, substrata and shading effects, and for that two experiments were led out. In the first one, seeds were previously soaked for 24 hours in water and in $100 \mathrm{mg} . \mathrm{L}^{-1}$ gibberellin solution and were sowed directly in cells trays in the following substrata: land and sand $(1: 1$ and $1: 2)$ and Plantmax ${ }^{\circledR}$. In the second experiment, $15 \mathrm{~cm}$ length seedlings were transplanted to polyethylene sacks filled out land + sand + poultry manure (1:1:1) partly decomposed and they were maintained at greenhouse for 15 days. Soon after, seedlings were transferred for the following conditions: shading (50\%) and full sun and they were $50 \mathrm{mg} . \mathrm{L}^{-1}$ and $150 \mathrm{mg} . \mathrm{L}^{-1}$ gibberellins solutions pulverized, as control seedlings water pulverized. Aroeira seeds should not be previously water or gibberellins imbibed before being sowed. The best substrata for aroeira seeds germination was Plantmax ${ }^{\circledR}$ without germinative treatments to reach higher than $80 \%$ of seedlings survival. The seedlings developed better at full sun light and the gibberellin. It was observed increment in height, diameter, foliar area and fresh and dry mass from aerial and root part when compared to shading situation. The gibberellins applications did not influence the aroeira seedlings initial growth characteristics.
\end{abstract}

Key words: Germinative pre-treatments, Myracrodruon urundeuva, Anacardiaceae, Savannah.

\section{INTRODUÇÃO}

Myracrodruon urundeuva Fr. Allemão é conhecida popularmente como aroeira e pertence à família Anacardiaceae, cuja distribuição natural limita-se à América do Sul. É nativa do Brasil e encontrada nas regiões Nordeste, Sudeste, Centro-Oeste e partes do Sul, associada a ambientes secos como cerrado, savanas e caatingas (SANTIN, 1989). É uma planta decídua, heliófila e seletiva xerófila, característica de terrenos secos e rochosos, ocorrendo em agrupamentos densos, tanto em formações abertas e secas, como em formações fechadas e úmidas (CARVALHO, 2003; SILVA et al., 2002).

A aroeira é uma espécie de grande importância econômica, em razão do aproveitamento da madeira, da extração de taninos e da utilização na farmacologia. A entrecasca da espécie possui propriedades antiinflamatórias, adstringentes, antialérgicas e cicatrizantes. As raízes são usadas no tratamento de reumatismo e as folhas são indicadas para o tratamento de úlceras (CARLINI et al., 2010). A madeira é caracterizada por ser dura, pesada e com alto conteúdo de tanino que confere resistência à

${ }^{1}$ Bióloga, Professora Doutora em Ciências dos Alimentos - Universidade Federal da Grande Dourados/UFGD - Faculdade de Ciências Agrárias - Dourados, MS, Brasil - Cx. P. 533 - 79804-970 - silvana.scalon@ufgd.edu.br

${ }^{2}$ Engenheiro Agrônomo, Doutorando em Agronomia - Universidade Estadual de Mato Grosso do Sul/UEMS - 79804-970 - Dourados, MS, Brasil - homero@uems.br

${ }^{3}$ Engenheira Agrônoma, PNPD/CAPES, Doutora em Engenharia Florestal - Universidade Federal da Grande Dourados/UFGD - Faculdade de Ciências Agrárias - Dourados, MS, Brasil - Cx. P. 533 - 79804-970 - tathianamasetto@ufgd.edu.br 
decomposição(QUEIROZ et al., 2002) e, por isso, é muito usada na fabricação de postes, dormentes, mourões e móveis. No entanto, pelos seus princípios alergênicos, a árvore não deve ser cultivada em locais de fácil acesso ao público (SANO; ALMEIDA, 1998).

Em decorrência dos múltiplos usos, a aroeira vem sofrendo um processo de exploração intensa e predatória, com a devastação de populações naturais. Além disso, deve-se salientar que a exploração seletiva da aroeira praticamente extinguiu os indivíduos de grande porte e em virtude do potencial econômico, seus recursos foram explorados de maneira indiscriminada ao longo de décadas, o que levou a espécie à lista oficial da flora ameaçada de extinção (INSTITUTO BRASILEIRO DO MEIO AMBIENTE E DOS RECURSOS NATURAIS IBAMA, 2008). Diante disso, torna-se imprescindível estimular o uso da espécie em reflorestamentos, visando à sua preservação e exploração sustentável. Assim, é necessário aumentar o conhecimento básico da germinação e propagação da aroeira, cuja ocorrência, utilidade e vulnerabilidade elevam a importância da espécie (NUNES et al., 2008).

Os estudos com germinação de sementes são geralmente realizados com o objetivo de ampliar os conhecimentos fisiológicos, verificando as respostas de germinação a fatores ambientais, causas e métodos de superação de dormência, conhecimentos morfológicos, acompanhamento do desenvolvimento do embrião e da plântula; para verificar o estádio de maturação das sementes e do efeito do processamento e armazenamento sobre a qualidade de sementes (BASKIN; BASKIN, 1998). De maneira geral, a germinação das sementes e o crescimento das plântulas são influenciados por fatores como água, luz, temperatura e substrato além do equilíbrio hormonal. O tipo de substrato influencia na germinação e no crescimento das plântulas, etapas que representam a fase mais crítica no ciclo de vida das plantas, e cuja sobrevivência está diretamente ligada à capacidade de germinar e aprofundar rapidamente as raízes no solo, desempenhando papel fundamental na sobrevivência inicial da planta (CASAGRANDE JÚNIOR et al., 1996; FIGUEIRÔA et al., 2004; HOFFMANN et al., 2001). Ainda nos dias de hoje, apesar da necessidade, existem poucas recomendações de substratos para mudas de espécies florestais nativas, dentre eles o Plantmax ${ }^{\circledR}$, a vermiculita e o pó de coco (PACHECO et al., 2006).

Os hormônios vegetais atuam de forma específica no desenvolvimento dos vegetais e dentre os quais, a giberelina está presente em diversos processos fisiológicos, como divisão e alongamento celular. Também atuam elevando a plasticidade da parede celular, preferencialmente em células jovens e meristemáticas, em decorrência da orientação transversal das microfibrilas de celulose (KERBAUY, 2004). Nas plântulas, os efeitos da giberelina aparecem no alongamento do caule, comprimento dos entrenós, área foliar e acúmulo de matéria seca (STEFANINI et al., 2002).

Para maximizar a obtenção de mudas de qualidade, também é necessária a determinação da sobrevivência de uma espécie e sua adaptação a condições de alta ou baixa luminosidade. Em geral, os diferentes graus de luminosidade causam mudanças fisiológicas e morfológicas na planta, e fazem com que as folhas apresentem anatomia e propriedades fisiológicas, que as capacitam a um uso efetivo da radiação solar disponível, sendo o grau dessa adaptação, ditado por características genéticas da planta em interação com o seu ambiente. A habilidade de algumas espécies em manter populações de plântulas e plantas jovens no sub-bosque de florestas está associada à capacidade das mesmas de incrementar a sobrevivência sob baixas irradiâncias, ou seja, tolerar o sombreamento (WALTERS; REICH, 2000).

A formação de mudas de espécies nativas com qualidade é fundamental para o estabelecimento de plantios comerciais e para o sucesso de programas de conservação e restauração de ecossistemas. Diante disso, estudos ecológicos básicos, principalmente relacionados aos aspectos ecofisiológicos de sementes e mudas de $M$. urundeuva, são essenciais para a preservação, manejo e restauração de populações dessa espécie (NUNES et al., 2008).

Diante da importância da espécie e da escassez de informações sobre métodos eficientes para sua propagação, objetivou-se, com este trabalho, avaliar os efeitos de tratamentos pré-germinativos, substratos durante a germinação das sementes e condições de luminosidade associadas à aplicação de giberelina no crescimento inicial das mudas de aroeira.

\section{MATERIAL E MÉTODOS}

As sementes de Myracrodruon urundeuva Fr. Allemão foram coletadas diretamente de 17 matrizes localizadas em remanescentes de vegetação, na cidade de Dourados-MS e levadas ao laboratório de Nutrição e Metabolismo de Plantas, da Faculdade de Ciências Agrárias (FCA), pertencente à Universidade Federal da Grande Dourados (UFGD), Dourados, MS. 
2.1 Efeitos de tratamentos pré-germinativos e substratos na germinação das sementes

Inicialmente, as sementes foram submetidas a dois tipos de tratamentos pré-germinativos: imersão em água; imersão em solução de giberelina a 100 ppm ambos durante 24 horas. As sementes que foram inoculadas logo após a coleta foram consideradas controle. A semeadura ocorreu em bandejas de isopor, divididas em células, nos seguintes substratos: terra e areia (1:1); terra e areia (1:2) ePlantmax ${ }^{\circledR}$. $O$ experimento foi conduzido em casa de vegetação, sendo avaliado diariamente até 40 dias após a semeadura quanto à porcentagem de germinação, índice de velocidade de germinação (POPINIGIS, 1985) e porcentagem de sobrevivência das plântulas. O critério para a avaliação da germinação foi a emissão de raiz primária com comprimento mínimo de cinco centímetros e plântulas normais.

$\mathrm{O}$ experimento foi conduzido em delineamento inteiramente casualizado, em esquema fatorial $3 \times 3$ (tratamentos pré-germinativos e tipos de substratos) com 4 repetições de 25 sementes cada. Os dados foram avaliados pelo teste $\mathrm{F}$ e havendo diferenças significativas, as médias foram comparadas pelo teste de Tukey a $5 \%$ de probabilidade, utilizando-se o programa estatístico SANEST (ZONTA et al., 1985).

\subsection{Efeitos do sombreamento e giberelina no crescimento inicial das mudas}

Plântulas com $15 \mathrm{~cm}$ de comprimento foram transplantadas para sacos de polietileno preenchidos com terra+areia+cama de aviário semidecomposta (1:1:1) como substrato, e foram mantidas em casa de vegetação durante 15 dias. Posteriormente, as mudas foram transferidas para as seguintes condições: $50 \%$ de sombreamento e pleno sol e receberam, por pulverização foliar, soluções de giberelina nas concentrações de 50 ppm e 150 ppme para o controle foi utilizado água destilada.

A cada trinta dias, ao longo de cinco meses, as mudas foram avaliadas quanto à altura e ao diâmetro de colo, com o auxílio de régua milimetrada e de paquímetro digital, respectivamente. Após 150 dias do transplantio, foram selecionadas três mudas de cada tratamento que foram avaliadas quanto a altura $(\mathrm{cm})$, diâmetro $(\mathrm{mm})$, a área foliar $\left(\mathrm{dm}^{2}\right)$ em integrador de área-foliar Li Cor 3000, massa fresca $(\mathrm{g})$ e seca $(\mathrm{g})$ da raiz e da parte aérea.

$\mathrm{O}$ experimento foi conduzido em delineamento inteiramente casualizado, em esquema fatorial $3 \times 2$ (pulverizações com giberelina e níveis de luz) com quatro repetições de 10 mudas cada. Os dados foram analisados pelo teste $\mathrm{F}$ e as médias foram comparadas pelo teste de Tukey a $5 \%$ de probabilidade.

\section{RESULTADOS E DISCUSSÃO}

Os resultados revelaram que não houve interação significativa entre os tratamentos pré-germinativos e os substratos na qualidade fisiológica de sementes de aroeira. A semeadura no substrato Plantmax® proporcionou a maior porcentagem e índice de velocidade de germinação para as sementes de aroeira em relação às duas proporções testadas da mistura terra+areia (Tabela 1). Possivelmente, o fato do substrato Plantmax $®$ apresentar maior quantidade de matéria orgânica e assim, apresentar maior disponibilidade de água para a embebição das sementes pode ter acelerado o processo germinativo das sementes de aroeira nessa condição, sem interferir na disponibilidade de oxigênio necessária para a realização da respiração na fase inicial da germinação das sementes. De acordo com Filgueira (2000), o Plantmax® absorve até cinco vezes o próprio volume em água. $\mathrm{Na}$ presente pesquisa, a maior porcentagem e índice de velocidade de germinação observadas com o Plantmax ${ }^{\circledR}$ assemelhou-se ao observado por Bezerra et al. (2004), com sementes de moringa (Moringa oleifera Lam.). Pacheco et al. (2006) encontraram germinação máxima de $93 \%$ para sementes de aroeira semeadas sobre pó de coco, e relataram que esse substrato também tem alta capacidade de retenção de água e porosidade. De maneira geral, para as sementes de aroeira,

Tabela 1 - Porcentagem de germinação (G), índice de velocidade de germinação (IVG) e porcentagem de sobrevivência (S) de sementes de aroeira semeadas em diferentes substratos e submetidas a diferentes tratamentos pré-germinativos.

Table 1 - Germination percentage $(G)$, germination speed index $(I V G)$ and survival percentage $(S)$ of aroeira seeds at different substrata and submitted to germination treatments.

\begin{tabular}{lccc}
\hline & $\mathrm{G}$ & IVG & $\mathrm{S}$ \\
\hline Plantmax & $34,77 \mathrm{a}$ & $1,02 \mathrm{a}$ & $98,41 \mathrm{a}$ \\
Terra+Areia 1:1 & $14,04 \mathrm{~b}$ & $0,28 \mathrm{~b}$ & $87,03 \mathrm{a}$ \\
Terra+Areia 1:2 & $17,73 \mathrm{~b}$ & $0,36 \mathrm{~b}$ & $87,03 \mathrm{a}$ \\
Controle & $39,22 \mathrm{a}$ & $0,88 \mathrm{a}$ & $94,33 \mathrm{a}$ \\
Água & $13,29 \mathrm{~b}$ & $0,38 \mathrm{~b}$ & $83,33 \mathrm{a}$ \\
GA100 mg.L & $14,04 \mathrm{~b}$ & $0,39 \mathrm{~b}$ & $83,33 \mathrm{a}$ \\
\hline CV $(\%)$ & 34,21 & 36,78 & 37,09 \\
\hline
\end{tabular}

Médias seguidas pela mesma letra minúscula na coluna não diferem entre si pelo teste de Tukey a $5 \%$ de probabilidade. Averages followed by the same letter in the columns do not differ by the Tukey test at $5 \%$ of probability.

Cerne, Lavras, v. 18, n. 4, p. 533-539, out./dez. 2012 
inicialmente observou-se reduzida porcentagem de germinação e, posteriormente, elevada porcentagem de sobrevivência das plântulas (acima de $85 \%$ ) em todos os substratos testados, que não diferiram entre si estatisticamente.

A semeadura das sementes de aroeira sem os tratamentos pré-germinativos proporcionou índices de germinação superiores estatisticamente em relação aos encontrados para as sementes previamente embebidas em água e giberelina por 24 horas, que não diferiram entre si estatisticamente (Tabela 1). Resultados semelhantes sobre a aplicação de tratamentos pré-germinativos em sementes de aroeira foram observados por Dorneles et al. (2005), quando a aplicação de giberelina, citocinina, nitrato de potássio e água não proporcionou diferença significativa na germinação das sementes, e as que foram semeadas diretamente apresentaram resultados médios de $60 \%$ de germinação. Sementes de $M$. urundeuva escarificadas mecanicamente com lixa apresentaram $93 \%$ de germinaçãoe índice de velocidade de germinação de 7,27 (PACHECO et al., 2006), bastante superior ao encontrado na presente pesquisa com as sementes do controle que apresentaram 0,88 de IVG. (Tabela 1). Guedes et al. (2011) observaram 1,56 de IVG e 60\% de germinação para sementes de aroeira sem tratamentos pré-germinativos e semeadas em Plantmax ${ }^{\circledR}$.

a)

—altura $\square$ diâmetro

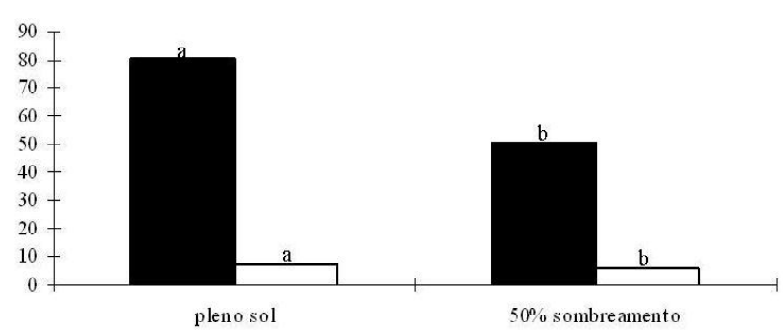

c) massa fresca de raiz $\square$ massa fresca de parte aérea

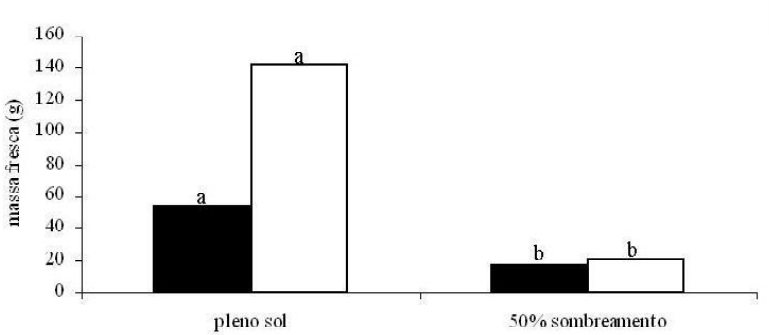

Entretanto, sugere-se que as discrepâncias nos resultados obtidos podem ser relacionadas com a variabilidade genética existente, local de ocorrência da espécie e fatores intrínsecos às sementes, pois a dormência existente em sementes de aroeira é a fisiológica, que é causada por mecanismos inibitórios, envolvendo os processos metabólicos e do desenvolvimento (CARDOSO, 2004), cujo controle também pode estar associado com as giberelinas, que são promotoras de germinação e da ativação do metabolismo voltado ao alongamento embrionário (RICHARDS et al., 2001). Embora não fossem detectadas diferenças estatísticas entre os tratamentos pré-germinativos para a sobrevivência de plântulas de aroeira, a ausência de tratamentos das sementes permitiu resultados numéricos superiores aos encontrados para as sementes embebidas em água e giberelina.

Pela análise de crescimento das mudas com mais de 200 dias de idade (segundo experimento), foram observadas diferenças significativas para todas as características avaliadas, constatando-se maior crescimento e desenvolvimento das mudas a pleno sol (100\%) (Figuras 1a, 1b, 1c e 1d). Esse comportamento é característico de espécies heliófitas que desenvolvem melhor na condição de maior disponibilidade de luz.

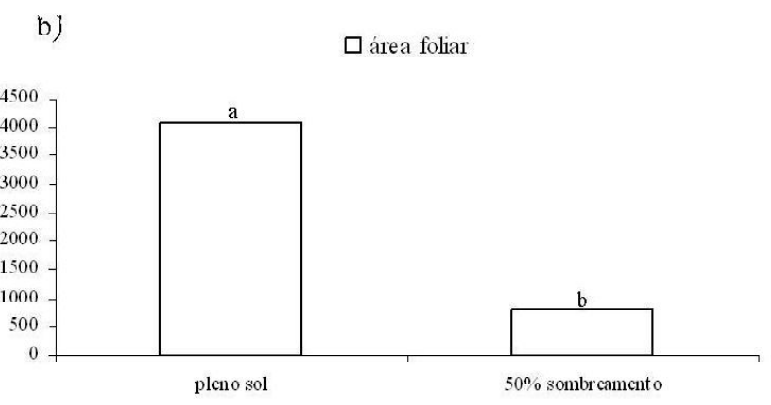

d) massa seca de raiz $\square$ massa seca de parte aérea

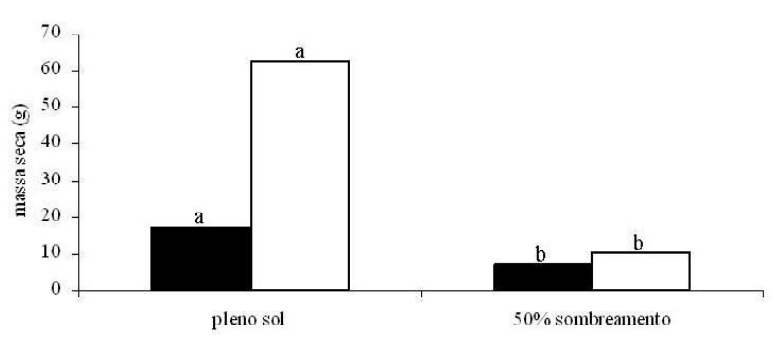

Figura 1 - Altura (cm), diâmetro (mm) (a), área foliar $\left(\mathrm{dm}^{2}\right)(\mathrm{b})$, massas frescas de raiz e de parte aérea (g) (c) e massas secas de raiz e de parte aérea (g) (d) de mudas de aroeira cultivadas a pleno sol e sob 50\% de sombreamento. Significativo a $5 \%$ pelo teste F.

Figure 1 - Height, diameter $(\mathrm{cm})(a)$, foliar surface $\left(d^{2}\right)^{2}(b)$, root and aerial part fresh mass $(\mathrm{g})(\mathrm{c})$ and root and aerial part dried mass $(g)(d)$ from full sun and 50\% shading aroeira seedlings. Significant at $5 \%$ F test.

Cerne, Lavras, v. 18, n. 4, p. 533-539, out./dez. 2012 
Por outro lado, Leite (2002) relata que as mudas de aroeira são sensíveis à luz e recomenda o sombreamento no momento do plantio. Silva et al. (2002) ao estudar o efeito da luz na germinação das sementes de aroeira, relatam que o caráter de luz foi apenas quantitativo, uma vez que as sementes germinaram tanto na presença como na ausência de luz. Contudo, no presente trabalho, houve redução significativa da altura e diâmetro de colo de plantas que permaneceram sob $50 \%$ de sombreamento em relação ao pleno sol.

A redução significativa da área foliar em condição de sombreamento pode explicar o menor crescimento das mudas (Figura 1b). As massas fresca (Figura 1c) e seca (Figura 1d) de raiz e de parte aérea das plantas também sofreram influência do sombreamento após 200 dias, indicando que não houve adaptação das mudas às condições de ambiente estabelecidas. Kozlowski (1962 citado por FONSECA et al., 2002) relatou que o aumento do sombreamento diminui a fotossíntese e, consequentemente, a quantidade de fotoassimilados e reguladores de crescimento, causando redução do diâmetro de colo das mudas. Para o autor, a fotossíntese, apresenta uma relação mais direta com o crescimento em diâmetro do que com a altura.

A aplicação de giberelina não influenciou significativamente o crescimento das mudas de aroeira, que não variou entre as doses e disponibilidades de luz, durante o período avaliado (Tabela 2). Observa-se na literatura que os níveis endógenos de giberelina ativa, regulam sua própria síntese por ativar ou inibir a transcrição de genes para enzimas que participam da biossíntese ou da degradação da giberelina. A luz regula a biossíntese de giberelina por meio da regulação da transcrição dos genes de degradação da giberelina e também causam um decréscimo na capacidade de resposta do alongamento do caule à presença de giberelina. Assim, quando uma planta cresce sob a luz, a taxa de extensão diminui, em razão da regulação por mudanças nos níveis hormonais ou na sensibilidade aos reguladores de crescimento (TAIZ; ZEIGER, 2004).

O estudo da aplicação de ácido giberélico no presente trabalho se justificou uma vez que, os resultados em outras espécies também variaram em função da dose utilizada. Scalon et al. (2006) também não observaram o crescimento das plântulas de orelhade-macaco (Enterolobium contortisiliqunn (Vell.) Morong) com a aplicação de doses de giberelina. Leonel e Pedrozo (2005) relataram que os tratamentos realizados com o biorregulador proporcionaram incrementos significativos na altura de plantas e no número de folhas de maracujazeiro-doce (Passiflora alata Dryander), onde os melhores resultados estiveram associados à dosagem de GA 300 mg.L L $^{-1}$. As mudas de sangra-d'água (Croton urucurana Baill.) apresentaram crescimento semelhante tanto a pleno sol, quanto sob $50 \%$ de sombreamento, sem necessitar de tratamento hormonal com giberelina (SCALON et al., 2008). A aplicação do ácido giberélico foi eficiente na promoção do crescimento de mudas de palmeira-ráfia (Rhapis excelsa (Thunb) Henry ex Rehder), sendo esse incremento significativo no comprimento dos pecíolos, lâminas foliares e altura da planta (TAVARES et al., 2007). Malavasi et al. (2011) recomendaram a pré-embebição de sementes de tarumã (Vitex montevidensis Cham.) em 100 a $200 \mathrm{mg} . \mathrm{L}^{-1} \mathrm{de}$ giberelina para obter elevada porcentagem e velocidade de germinação das sementes.

Sementes de aroeira não necessitam de préembebição em água ou em giberelina antes da semeadura.

Tabela 2 - Altura $(\mathrm{cm})$, diâmetro (mm), massas frescas de raiz (MFR) e de parte aérea (MFPA) (g), área foliar $(\mathrm{AF})\left(\mathrm{dm}^{2}\right)$, massas seca de raiz (MSR) e de parte aérea (MSPA) (g) de mudas de aroeira pulverizadas com soluções de giberelina e cultivadas a pleno sol e sob $50 \%$ de sombreamento.

Table 2 - Height (cm), diameter $(\mathrm{mm})$, root (MFR) and aerial part fresh mass (MFPA) $(\mathrm{g})$, foliar surface $(\mathrm{AF})\left(\mathrm{dm}^{2}\right), d r y$ root $(M S R)(g)$ and aerial part $(M S P A)(g)$ from gibberellins pulverized aroeira seedlings and cultivated at full sun and $50 \%$ shading.

\begin{tabular}{cccccccc}
\hline & Altura & Diâmetro & MFR & MFPA & AF & MSR & MSPA \\
\hline Testemunha & $68,87 \mathrm{a}$ & $6,53 \mathrm{a}$ & $41,08 \mathrm{a}$ & $74,26 \mathrm{a}$ & $2154,83 \mathrm{a}$ & $13,90 \mathrm{a}$ & $37,91 \mathrm{a}$ \\
GA 50 ppm & $64,48 \mathrm{a}$ & $6,52 \mathrm{a}$ & $33,75 \mathrm{a}$ & $71,21 \mathrm{a}$ & $2101,00 \mathrm{a}$ & $11,91 \mathrm{a}$ & $31,99 \mathrm{a}$ \\
GA 150 ppm & $63,82 \mathrm{a}$ & $6,33 \mathrm{a}$ & $32,08 \mathrm{a}$ & $68,25 \mathrm{a}$ & $2069,33 \mathrm{a}$ & $11,26 \mathrm{a}$ & $30,03 \mathrm{a}$ \\
\hline
\end{tabular}

Médias seguidas pela mesma letra na coluna não diferem entre si ao nível de $5 \%$ de probabilidade. Averages followed by the same letter in the columns do not differ by the Tukey test at $5 \%$ of probability. 
O melhor substrato para a germinação das sementes é o Plantmax ${ }^{\circledR}$, sem necessidade de tratamentos prégerminativos para a obtenção de sobrevivência de plântulas acima de $80 \%$. As mudas desenvolvem melhor a pleno sol, sendo observado incremento em altura, diâmetro, área foliar, massas fresca e seca da parte aérea e da raiz em relação ao sombreamento. A aplicação de giberelina não influencia as características de crescimento inicial das mudas de aroeira.

\section{REFERÊNCIAS}

BASKIN, C. C.; BASKIN, J. M. Seeds: ecology, biogeography and evolution of dormancy and germination. New York: Academic, 1998.

\section{BEZERRA, A. M. E.; MOMENTÉ, V. G.; MEDEIROS}

FILHO, S. Germinação de sementes e desenvolvimento de plântulas de moringa (Moringa oleifera Lam.) em função do peso da semente e do tipo de substrato. Horticultura Brasileira, Brasília, v. 22, n. 2, p. 295-299, abr./jun. 2004.

CARDOSO, V. J. M. Dormência: estabelecimento do processo. In: FERREIRA, A. G.; BORGHETTI, F. (Ed.). Germinação: do básico ao aplicado. Porto Alegre: Artmed, 2004.

CARLINI, E. A.; DUARTE-ALMEIDA, J. M.; RODRIGUES, E.; TABACH, R. Antiulcer effect of the pepper trees Schinus terebinthifolius Raddi (aroeira-da-praia) and Myracrodruon urundeuva Allemão, Anacardiaceae (aroeira-do-sertão). Revista Brasileira de Farmacognosia, Curitiba, v. 20, n. 2, p. 140-146, abr./maio 2010.

CARVALHO, P. E. R. Espécies arbóreas brasileiras. Brasília: EMBRAPA Informação Tecnológica, 2003. 1039 p.

CASAGRANDE JÚNIOR, J. G.; VOLTOLINE, J. A.; HOFMANN, A.; FACHINELLO, J. C. Efeito de materiais orgânicos no crescimento de mudas de araçaizeiro (Psidium cattleyanum Sabine). Revista Brasileira de Agrociência, Pelotas, v. 2, n. 3, p. 187-191, 1996.

DORNELES, M. C.; RENAL, M. A.; SANTANA, D. G. Germinação de sementes recém-colhidos de Myracrodruon urundeuva Allemão (Anacardiaceae) ocorrendo no cerrado do Brasil Central. Revista Brasileira de Botânica, São Paulo, v. 28, n. 2, p. 399-408, 2005.
FIGUEIRÔA, J. M.; BARBOSA, D. C. A.; SIMABUKURO, E. A. Crescimento de plantas jovens de Myracrodruon urundeuva Allemão (Anacardiaceae) sob diferentes regimes hídricos. Acta Botânica Brasílica, São Paulo, v. 18, n. 3, p. 573-580, 2004.

FILGUEIRA, F. A. R. Novo manual de olericultura: agrotecnologia moderna na produção e comercialização de hortaliças. Viçosa, MG: UFV, 2000. 402 p.

FONSECA, E. P.; VALÉRI, S. V.; MIGLIORANZA, É.; FONSECA, N. A. N.; COUTO, L. Padrão de qualidade de mudas de Trema micrantha (L.) Blume, produzidas sob diferentes períodos de sombreamento. Revista Árvore, Viçosa, v. 26, n. 4, p. 515-523, jul./ago. 2002.

GUEDES, R. S.; ALVES, E. U.; GONÇALVES, E. P.; COLARES, P. N. Q.; MEDEIROS, M. S.; VIANA, J. S. Germinação e vigor de sementes de Myracrodruon urundeuva Allemão em diferentes substratos e temperaturas. Revista Árvore, Viçosa, v. 35, n. 5, p. 975-982, maio 2011.

INSTITUTO BRASILEIRO DO MEIO AMBIENTE E DOS RECURSOS NATURAIS. Lista oficial de flora ameaçada de extinção. Disponível em: <http://www.ibama.gov.br/flora/ extincao.htm>. Acesso em: 30 jul. 2010.

KERBAUY, G. B. Fisiologia vegetal. Rio de Janeiro: Guanabara Koogan, 2004. v. 1, 452 p.

LEITE, E. J. State-of-knowledge on Myracrodruon urundeuva Fr. Allemão (Anacardiaceae) for genetic conservation in Brazil. Perspectives in Plant Ecology, Evolution and Systematics, Jena, v. 5/3, p. 193-206, 2002.

LEONEL, S.; PEDROSO, C. J. Produção de mudas de maracujazeiro-doce com o uso de biorregulador. Revista Brasileira de Fruticultura, Jaboticabal, v. 27, n. 1, p. 107109, abr. 2005.

MALAVASI, M. M.; DIAS, G. B.; MALAVASI, U. C. Effect of gibberellic acid and temperature on germination of Vitex montevidensis Cham. Cerne, Lavras, v. 17, n. 2, p. 203-207, abr./jun. 2011.

NUNES, Y. R. F.; FAGUNDES, M.; ALMEIDA, H. S.; VELOSO, M. D. M. Aspectos ecológicos da aroeira (Myracrodruon urundeuva Allemão - Anacardiaceae): fenologia e germinação de sementes. Revista Árvore, Viçosa, v. 32, n. 2 , p. 248-252, mar./abr. 2008.

Cerne, Lavras, v. 18, n. 4, p. 533-539, out./dez. 2012 
PACHECO, M. V.; MATOS, V. P.; FERREIRA, R. L. C.; FELICIANO, A. L. P.; PINTO, K. M. S. Efeito de temperatura e substrato na germinação de sementes de Myracrodruon urundeuva Fr. All. (Anacardiaceae).

Revista Árvore, Viçosa, v. 30, n. 3, p. 359-367, maio/jun. 2006.

POPINIGIS, F. Fisiologia da semente. Brasília: AGIPLAN, 1985. $289 \mathrm{p}$.

QUEIROZ, C. R. A. A.; MORAIS, S. A. L.; NASCIMENTO, E. A. Caracterização dos taninos da aroeira-preta (Myracrodruon urundeuva). Revista Árvore, Viçosa, v. 26, n. 4, p. 485-492, jul./ago. 2002.

RICHARDS, D. E.; KING, K. E.; AIT-ALI, T.; HARBERD, N. P. How gibberellin regulates plant growth and development: a molecular genetic analysis of gibberellin signaling. Annual Review of Plant Physiology and Plant Molecular Biology, Palo Alto, v. 52, p. 67-88, 2001.

SANO, S. M.; ALMEIDA, S. P. (Ed.). Cerrado: ambiente e flora. Planaltina: EMBRAPA, 1998. 556 p.

SANTIN, D. A. Revisão taxonômica do gênero Astronium Jacq. e reavaliação do gênero Myracrodruon Fr. Alem (Anacardiaceae). 1989. 178 f. Dissertação (Mestrado) - Universidade Estadual de Campinas, Campinas, 1989.

SCALON, S. P. Q.; KODAMA, F. M.; SCALON FILHO, H.; MUSSURY, R. M. Crescimento inicial de mudas de sangra-d'água (Croton urucurana Baill.) sobsombreamento e aplicação de giberelina. Revista Brasileira de Plantas Medicinais, Botucatu, v. 10, n. 3, p. 61-66, 2008.
SCALON, S. P. Q.; MUSSURY, R. M.; GOMES, A. A.; SILVA, K. A.; WATHIER, F; SCALON FILHO, H.

Germinação e crescimento inicial da muda de orelha de macaco (Enterolobium contortisiliqunn (vell Morong): efeito de tratamentos químicos e luminosidade. Revista Árvore, Viçosa, v. 30, n. 4, p. 1401-1407, jul./ago. 2006.

SILVA, L. M. M.; RODRIGUES, T. J. D.; AGUIAR, I. B. Efeito da luz da temperatura na germinação de sementes de aroeira (Myracrodruon urundeuva Allemão). Revista Árvore, Viçosa, v. 26, n. 6, p. 2261-2267, nov./dez. 2002.

STEFANINI, M. B.; RODRIGUES, S. D.; MING, L. C. Ação de fitorreguladores no crescimento da erva-cidreira-brasileira.

Horticultura Brasileira, Brasília, v. 20, n. 1, p. 18-23, mar. 2002.

TAIZ, L.; ZEIGER, F. Fisiologia vegetal. Porto Alegre: Artmed, 2004. 719 p.

TAVARES, A. R.; AGUIAR, F. F.; SADO, M.; KANASHIRO, S.; CHU, E. P.; LIMA, G. P. P.; LUZ, P. B.; MODOLO, V. A. Efeito da aplicação de ácido giberélico no crescimento da palmeira-ráfia. Revista Árvore, Viçosa, v. 31, n. 6, p. 9991004, nov./dez. 2007.

WALTERS, M. B.; REICH, P. B. Low light carbon balance and shade tolerance in the seedlings of woody plants: do winter deciduous and broad-leaved evergreen species differ? New Phytologist, Cambridge, v. 143, p. 143-154, 2000.

ZONTA, E. F.; MACHADO, A. A.; SILVEIRA JÚNIOR, P. Sistema de análise estatística (SANEST) para microcomputador, versão 1.0. In: SIMPÓSIO DE ESTATÍSTICA APLICADA À EXPERIMENTAÇÃO AGRONÔMICA, 1985, Piracicaba. Anais... Piracicaba: FEALQ, 1985. p. 74-90. 